\title{
Small proline-rich proteins 2 are noncoordinately upregulated by IL-6/STAT3 signaling after bile duct ligation
}

Isao Nozaki ${ }^{1,2}$, John G Lunz III ${ }^{1,2,3}$, Susan Specht ${ }^{1,3}$, Donna B Stolz ${ }^{4}$, Kenichi Taguchi ${ }^{1,2}$, Vladimir M Subbotin ${ }^{5}$, Noriko Murase ${ }^{1,3}$ and Anthony J Demetris ${ }^{1,2}$

${ }^{1}$ Thomas E Starzl Transplantation Institute, Divisions of Transplantation, University of Pittsburgh Medical Center, Pittsburgh, PA, USA $;^{2}$ Department of Pathology, Divisions of Transplantation, University of Pittsburgh Medical Center, Pittsburgh, PA, USA; ${ }^{3}$ Department of Surgery, Divisions of Transplantation, University of Pittsburgh Medical Center, Pittsburgh, PA, USA; ${ }^{4}$ Department of Cell Biology and Physiology, University of Pittsburgh School of Medicine, Pittsburgh, PA, USA and ${ }^{5}$ Mirus Bio Corporation, Madison, WI, USA

Small proline-rich proteins 2 (SPRR2) are coordinately expressed with other epidermal differential complex (EDC) genes in the skin. They function as crosslinking proteins that form bridges between other proteins that comprise the cornified cell envelope, which is the major barrier against the environment. IL-6 is invariably produced at sites of biliary tract injury and IL-6-deficient (IL-6 ${ }^{-1}$ ) mice show impaired barrier function after bile duct ligation (BDL). Screening microarray analysis identified noncoordinate expression of SPRR2 as a candidate gene that is: (a) expressed in biliary epithelial cells (BEC); (b) IL-6 responsive; and (c) potentially related to biliary barrier function. Therefore, we studied in detail the regulation of BEC SPRR2A expression, in vitro; and tested the hypothesis that if BEC SPRR2 expression contributes to biliary barrier function, it should be increased after BDL in IL-6-wild type (IL-6 ${ }^{+/+}$) mice and not in IL-6 ${ }^{-1-}$ mice. In vitro studies confirmed that IL6/gp130-signaling, mediated primarily by signal transducer and activator of transcription 3 (STAT3), stimulated noncoordinate BEC SPRR2 expression. In vivo, noncoordinate upregulation of BEC SPRR2 expression after $\mathrm{BDL}$ was seen in the IL-6 ${ }^{+/+}$mice and was unrelated to squamous metaplasia. IL-6 $6^{-1-}$ mice showed deficient BEC SPRR2 expression after BDL associated with impaired barrier function, as evidenced by smaller diameters of obstructed ducts, decreased bile volume, and an inability to form 'white bile' compared to IL-6 $6^{+/+}$mice at 12 weeks after BDL. IL- 6 replacement therapy reversed the barrier defect in IL- $6^{-1-}$ mice after BDL, coincident with recovery of SPRR2A expression. SPRR2 in diseased mouse and human liver localized subjacent to the apical plasma membrane of BEC lining bile ducts, but was more diffusely expressed throughout the cytoplasm of cholangioles. In conclusion, BEC IL-6/gp130/STAT3 signaling noncoordinately upregulates BEC SPRR2 that appears to contribute to modification of the biliary barrier under conditions of stress.

Laboratory Investigation (2005) 85, 109-123, advance online publication, 22 November 2004; doi:10.1038/labinvest.3700213

Keywords: small proline-rich proteins; epithelial-mesenchymal transition; biliary; epithelia; interleukin-6

Small proline-rich proteins (SPRR) are encoded by a tandemly arranged four-member gene family contained within a 170-kilobase region of the epidermal differentiation complex (EDC). The EDC is a cluster of more than 50 genes located on chromosome $1 \mathrm{q} 21^{1-3}$ whose products are involved in terminal differentiation of the human epidermis, including precursors of the cornified cell envelope (CE)

Correspondence: Dr AJ Demetris, MD, University of Pittsburgh, E1548 Biomedical Science Tower, 200 Lothrop Street, Pittsburgh, PA 15261, USA.

E-mail: demetrisaj@upmc.edu

Received 24 June 2004; revised 8 October 2004; accepted 10 October 2004; published online 22 November 2004 (loricrin, involcrin, and SPRR), intermediate filament-associated proteins, and the S100 family of calcium-binding proteins. ${ }^{1,4}$

The SPRR genes encode for a series of highly homologous proteins that are critical components of the $\mathrm{CE}$, an effective barrier against the environment. ${ }^{2,3,5-7}$ Many members of the SPRR protein family differ by only one to three amino acids. Therefore, regulatory diversity appears to have been more important than diversification of protein structure during evolution of these genes. ${ }^{2}$ This implies that control of SPRR protein dosage is of major functional importance. ${ }^{2}$ As with other members of the EDC, ${ }^{5}$ SPRR genes can be coordinately regulated as part of the EDC (ie high expression of 
most EDC genes, as in papillomas, or very low expression of most genes, as in newborn skin), or noncoordinately regulated (eg high expression of the SPRR2 genes) to enable selective modification of a particular barrier. ${ }^{2,8}$

In the skin and other squamous epithelia, Sprr function primarily as crosslinking proteins, by forming bridges between other proteins, such as loricrin and tricohyalin, through the catalytic action of transglutaminases. ${ }^{9}$ In fact, the $\mathrm{CE}$ is made insoluble by the extensive crosslinking of several different proteins, which, at least in part, explains its rigidity and ability to protect against the environment. $^{9}$

SPRR2 genes are noncoordinately upregulated in situations that cannot be explained by squamous differentiation or formation of CE. Examples include greater than 100-fold increases seen in the intestine after small bowel resection ${ }^{10}$ or after introduction of commensal bacteria into germ-free mice. ${ }^{11,12}$ SPRR proteins are also expressed in ovarian epithelial cells, ${ }^{13}$ in uterine lining epithelium at certain stages of the estrous cycle, ${ }^{8,14}$ during development of the prostate gland, ${ }^{15}$ and in regenerating peripheral neurons. ${ }^{16}$ Except for neuronal regeneration, the physiologic significance of SPRR expression under these circumstances is assumed to be broadly related to barrier function because of their role in the skin. ${ }^{12}$ However, mechanisms of SPRR involvement in barrier function unrelated to squamous differentiation or CE are not understood.

Biliary epithelial cells (BEC) line the biliary tree and form an effective barrier in the liver against one of the most toxic biologic fluids in the body-bile. Virtually any biliary tree insult, such as obstruction, ${ }^{17-19}$ infection, ${ }^{19,20}$ or immunologic damage ${ }^{21-23}$ triggers increased BEC expression of $\mathrm{IL}^{-6}{ }^{24}$ Bile duct ligation (BDL), a maneuver that stresses and damages the biliary tree barrier, results in a reproducible model of rapidly decompensating biliary cirrhosis in IL-6-deficient (IL-6 ${ }^{-/-}$) mice because of impaired biliary barrier function. ${ }^{25}$ Screening gene array analysis suggested that noncoordinate upregulation of the BEC SPRR2 genes might be at least partially responsible for the phenotype observed in the IL- $6^{-/-}$mice. ${ }^{26}$

SPRR expression has not been previously described in the liver. Therefore, this initial study was carried out to investigate the (patho-)physiologic function(-s) of SPRR2 in the biliary tree. We analyzed in detail, the regulation of BEC SPRR $2 A$ expression, in vitro. Then we tested the hypothesis that if noncoordinate BEC SPRR expression contributes to selective modification of BEC barrier function, as in the skin and other mucosal sites, increased BEC SPRR2 expression should occur in IL-6-wild type (IL- $6^{+/+}$) mice, but not in IL- $6^{-/-}$ mice after BDL. A combination of results obtained in vitro and in vivo showed that within the liver, SPRR2 is expressed only in the BEC and is noncoordinately upregulated by IL-6/gp130/signal transducer and activator of transcription 3 (STAT3) signaling. Furthermore, deficient BEC SPRR2 expression in IL- $^{-1-}$ mice is associated with impaired barrier function after BDL, and treatment with exogenous IL-6 restores biliary tree integrity, coincident with recovery of SPRR2A levels.

\section{Materials and methods}

\section{Mice}

Eight to 14-week-old male IL-6 $6^{-1-}$ mice and littermate IL- $6^{+/+}$controls were used for the source of bile ducts for the primary mouse BEC cultures and the BDL studies under the University of Pittsburgh Institutional Animal Care and Use Committee Protocol \# 0101176A-1. The IL-6 ${ }^{-1-}$ mice were created by replacing a $2.1 \mathrm{~kb}$ fragment of the IL-6 gene containing the proximal promoter region and the first three exons with MC1-Neo poly(A)+ cassette, as reported by Poli et al. ${ }^{27}$ The original genetic background of the mice was approximately $75 \%$ C57BL/6, 20\% 129SV, and 5\% mixed F1. For these experiments, the mice were bred and maintained in the animal facility at the University of Pittsburgh on a standard diet of Purina Isopro 3000 (Purina, Richmond, IN, USA), which contains $5 \%$ fat.

\section{Cell Culture}

Primary cultures of mouse BEC and human BEC were prepared as previously reported. ${ }^{28,29}$ For all experiments, except where noted, BEC were cultured on collagen gels in simple serum-free medium (S-SFM), or complete serum-free medium (C-SFM). The constituents of these media were previously described. ${ }^{28,29}$ The MAPK inhibitor, PD98059 (Calbiochem, La Jolla, CA, USA) and recombinant mutein IL-6 (ImClone System, Somerville, NJ, USA) were used to treat the BEC in several experiments. An adenoviral vector coding for a dominant negative form of STAT3 (AdSTAT3-DN) and a control viral vector (AdGFP) (gifts from Dr J Park) were used to transiently transfect mouse BEC at a dose of $25 \mathrm{MOI}^{30}$ The AdSTAT3-DN and the AdGFP express green fluorescent protein (GFP) used to measure viral titers and transfection efficiency.

\section{High-Density Oligonucleotide Array Analysis}

BEC $\left(8 \times 10^{5}\right)$ from $\mathrm{IL}_{-6} 6^{+/}$and $\mathrm{IL}-6^{-/-}$mice were seeded into a $10 \mathrm{~cm}$ collagen-gel dish in C-SFM supplemented with $50 \mu \mathrm{g} / \mathrm{ml}$ bovine pituitary extract (BPE) and $10 \mathrm{ng} / \mathrm{ml}$ EGF for 7 days until the cultures were about $70 \%$ confluent. The medium was removed and the cells were washed twice with PBS and incubated in S-SFM for $24 \mathrm{~h}$ and then changed to C-SFM for $48 \mathrm{~h}$, as in previous experiments. ${ }^{28}$ Total RNA was then extracted from the BEC 
by TRIzol reagent (Invitrogen, Carlsbad, CA, USA), and purified with Qiagen RNeasy kit (Qiagen, San Diego, CA, USA). Five micrograms of total RNA were used in the first strand complementary DNA (cDNA) synthesis with T7-d(T)24 primer (GGCCAGTGAATT GTAATACGACTCACTATAGGGAGGCGG-(dT)24) by SuperscriptTM II (Invitrogen). The second strand cDNA synthesis was carried out at $16^{\circ} \mathrm{C}$ by adding Escherichia coli DNA ligase, E. coli DNA polymerase I and RNaseH in the reaction. This was followed by the addition of T4 DNA polymerase to blunt the ends of newly synthesized cDNA. The cDNA was purified through phenol/chloroform and ethanol precipitation. The purified cDNAs were then incubated at $37^{\circ} \mathrm{C}$ for $4 \mathrm{~h}$ in an in vitro transcription reaction to produce cRNA labeled with biotin using MEGAscriptTM system (Ambion, Inc, Austin, TX, USA). In all, 15-20 mg of cRNA were fragmented by incubating in a buffer containing $200 \mathrm{mM}$ Trisacetate (pH 8.1), $500 \mathrm{mM} \mathrm{KOAc}$, and $150 \mathrm{mM}$ $\mathrm{MgOAc}$ at $95^{\circ} \mathrm{C}$ for $35 \mathrm{~min}$. The fragmented cRNA were then hybridized with a pre-equilibrated Affymetrix chips (U74A ver.2; Affymetrix Inc., Santa Clara, CA, USA) at $45^{\circ} \mathrm{C}$ for $14-16 \mathrm{~h}$. After the hybridization cocktails were removed, the chips were washed in a fluidic station with low-stringency buffer $(6 \times$ SSPE, $0.01 \%$ Tween $20,0.005 \%$ antifoam) for 10 cycles (2 mixes/cycle) and stringent buffer (100 mM MES, $0.1 \mathrm{M} \mathrm{NaCl}$ and $0.01 \%$ Tween 20) for four cycles (15 mixes/cycle), and stained with SAPE (streptoavidin phycoerythrin). This was followed by incubation with biotinylated mouse antiavidin antibody, and restained with SAPE. The chips were scanned in a HP ChipScanner (Affymetrix Inc.) to detect hybridization signals. Hybridization data were analyzed through Microarray suite 5.0 automatic software and GeneChip Expression Analysis software (Affymetrix Inc.) for a comparitive analysis of two samples.

\section{SYBR Green Quantitative Real-Time RT-PCR}

Total RNA pellets were resuspended in RNase-free water, followed by the removal of potential contaminating DNA by treatment with DNase I (Invitrogen). Total RNA was used for reverse transcription with an oligo dT and a SuperscriptTM II (Invitrogen) to generate first strand cDNA. Mouse SPRR2A, mouse
GAPDH, human SPRR2, and human $\beta$-actin mRNA expressions were quantified in duplicate by SYBR Green two step, real-time RT-PCR on an ABI PRISM 7000 Sequence Detection System (PE Applied Biosystems, Foster City, CA, USA). PCR reaction mixture was prepared using SYBR Green PCR Master Mix (PE Applied Biosystems). The forward $(\mathrm{F})$ and reverse (R) primers were selected using Primer Express software (PE Applied Biosystems), and are shown in Table 1. The identities of each PCR fragment were confirmed with DNA sequencing (data not shown). The standard curve was constructed with five-fold serial dilutions of total cDNA from the IL- $6^{+/+}$BEC or primary human BEC. The five points always showed a strong linear relationship $\left(R^{2}>0.99\right)$ between the threshold cycle $\left(C_{\mathrm{t}}\right)$ and the initial copy number of each cDNA (data not shown). All gene expressions were normalized with the level of mouse GAPDH or human $\beta$-actin mRNA used as an internal control. Dissociation curve analyses were performed for each reaction to ensure amplification of the specific product. To exclude PCR amplification of contaminating genomic DNA, RT-negative controls (samples containing RNA that were not reverse transcribed) were performed.

\section{Operative Procedures and Isolation of the Biliary Tree after BDL}

Under methoxyflurane anesthesia, all mice were aseptically subjected to double ligation of the common bile duct below the bifurcation and single ligation above the pancreas with dissection between the distal and proximal knots. Animals $(n=3-5$ in each group at each time point) were killed at 0 and $4 \mathrm{~h}$, and 1,3 , and 7 days and 6,7 , and 12 weeks after BDL. For mice killed during the first week after BDL, RNA was extracted separately from the 'biliary tree' fraction, which includes the biliary epithelium as well as the surrounding connective tissue and blood vessels, but not hepatocytes, and the 'hepatocyte' fraction. ${ }^{17}$ For mice killed after 1 week, RNA was extracted from whole liver; it was not possible to mechanically separate the biliary tree fraction from the hepatocyte fraction because of fibrosis.

To determine the effect of IL-6 replacement therapy on $\mathrm{IL}_{-} 6^{-/-}$mice, a group of $\mathrm{IL}^{-6^{-/-}}$mice

Table 1 Primers used in real-time RT-PCR

\begin{tabular}{lllll}
\hline Gene & Genbank $\#$ & Forward primer $\left(5^{\prime}-3^{\prime}\right)$ & Reverse primer $\left(5^{\prime}-3^{\prime}\right)$ & Product size \\
\hline mSPRR2A & AJ005559 & CCTTGTCCTCCCCAAGCG & AGGGCATGTTGACTGCCAT & 144 bp \\
mGAPDH & M32599 & TGGCAAAGTGGAGATTGTTGCC & AAGATGGTGATGGGCTTCCCG & 156 bp \\
hSPRR2 $2^{\mathrm{a}}$ & X53064, AF333952, AF333954 & AGTGCCAGCAGAAATATCCTCC & GAACGAGGTGAGCCAAATATCC & 131 bp \\
hSPRR $2 A^{\mathrm{b}}$ & X53064 & AGTGCCAGCAGAAATATCCTCC & TGCTCTTGGGTGGATACTTTGA & 69 bp \\
h $\beta$-actin & X00351 & AGGCATCCTCACCCTGAAGTA & CACACGCAGCTCATTGTAGA & 103 bp \\
\hline
\end{tabular}

${ }^{\mathrm{a}}$ This pair of primers was designed to detect $h S P R R 2 A, h S P R R 2 B$, and $h S P R R 2 D$ cDNAs, and used in Figure 1c.

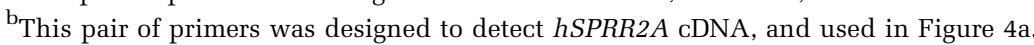


subjected to long-term BDL was treated via subcutaneous injection with either recombinant mutein IL-6 (ImClone System, Somerville, NJ, USA), a modified version of recombinant human (rh)IL-6 protein,,$^{31}$ or with normal saline as a control. Daily treatment was started at 6 weeks after BDL and continued for 1 or 6 weeks, at a dose of $1 \mu \mathrm{g} / \mathrm{g} \mathrm{BW} /$ day in a $0.04 \%$ solution of pyrogen-free normal saline. IL-6 treatment was started at 6 weeks after BDL because that is when the IL- $6^{-1-}$ mice started to decompensate and die. ${ }^{25}$ Before that time there are some phenotypic differences, but the hard end point of a difference in survival did not start to become apparent after this time point.

\section{Morphometric Evaluation of Intrahepatic Biliary Tree}

Determination of bile duct size was carried out on IL- $6^{-/-}$and IL- $6^{+/+}$mouse livers at 12 weeks after BDL using hematoxylin-eosin (H\&E)-stained sections with the aid of a morphometric graticule (Sigma-Aldrich, St Louis, MO, USA) installed into the eyepiece of an OLYMPUS BX40 microscope. The graticule was divided into $50 \mathrm{U}$ with subdivisions. Using a micrometer calibration plate (VWR), one unit of the graticule was determined as $6.25 \mu \mathrm{m}$ under magnification $\times 400$. To ensure uniformity, one $5 \mu \mathrm{m}$ section was obtained from the middle of the left lateral lobe of each liver. The five largest intrahepatic bile ducts were determined in each section and the shortest diameters were measured (IL- $6^{+/+}, n=19$; 95 bile ducts total); (IL- $6^{-/-}, n=21$; 105 bile ducts total) as a number of units. The average shortest diameter of the bile ducts was calculated for each animal, and then values for both groups were analyzed. Significance of $P$-value was calculated by Student's $t$-test for two-sample unequal variance. All measurements were performed on coded slides so the origin of the animal was unknown.

\section{Western Blot Analysis}

Protein extraction and Western blotting were carried out as previously described, ${ }^{32}$ with minor modifications. Briefly, total protein was extracted from the cultured cells using Chaps Cell Extract Buffer (Cell Signaling Technology, Inc., Beverly, MA, USA), and aliquots were measured for protein concentration using the BCA protein assay kit (Pierce, Rockford, IL, USA). In all $50 \mu \mathrm{g}$ of total proteins were separated by SDS-PAGE using 15\% SDS-page gel or $10-20 \%$ gradient Tris-HCl precast-gel (Bio-Rad, Hercules, CA, USA). The separated proteins were transferred to nitrocellulose membranes that were subsequently incubated with rabbit anti-SPRR2 antibody (Apotech Corporation, Geneva, Switzerland), mouse antiV5 antibody (Invitrogen), mouse anti-E-cadherin antibody (BD Biosciences, San Diego, CA, USA), rabbit anti-human fibronectin antibody (Dako,
Carpinteria, CA, USA), mouse anti-vimentin antibody (BioGenex, San Ramon, CA, USA), and mouse anti- $\beta$-actin (Clone AC-15; Sigma, St Louis, MI, USA). All signals were detected using enhanced chemiluminescence reagents (NEN; Life Science Products, Boston, MA, USA).

\section{Immunofluorescence Studies}

Acetone-fixed frozen sections of IL- $6^{+/+}$and IL- $6^{-/-}$ mice liver tissue at 12 weeks after BDL and human liver tissue affected with primary biliary cirrhosis (PBC) were subjected to immunohistochemical and immunofluorescence staining. The human tissues were obtained from archived samples maintained in the Department of Pathology according to exempt Institutional Review Board protocol number 010259. Tissue sections and cells were washed three times in PBS, then three times with PBS supplemented with $0.5 \% \mathrm{BSA}$ and $0.15 \%$ glycine (PBG) for $3 \times 5 \mathrm{~min}$ each. The slides were washed once with PBG, blocked with $20 \%$ normal goat serum in PBG for $40 \mathrm{~min}$ and then washed once with PBG. Primary antibodies were added to cells in PBG at a 1:100 dilution and incubated at room temperature for $1 \mathrm{~h}$; rabbit anti-SPRR2 antibody (Apotech Corporation) and mouse anti-human cytokeratin antibody (AE1/ AE3, Dako). The polyclonal anti-SPRR2 antibody was raised against human SPRR2, but the SPRR2 locus is highly conserved between mouse and human. ${ }^{8}$ The main inter- and intraspecies difference is in the number of repeats in the central domain, that is, from three repeats in all human SPRR2s identified so far to a range of 2.7-7 repeats in mouse Sprr2s. The significance of the variation in the repeat number for the function of the SPRR2 proteins as crossbridging proteins remains to be established. $^{8}$

Slides were then washed four times in PBG and the secondary antibodies added at the designated dilutions for $1 \mathrm{~h}$ at room temperature (Goat antirabbit Cy3, goat anti-mouse Cy3 1:1000, Jackson ImmunoResearch Laboratories, West Grove, PA, USA). Then the slides were washed three times in PBG and three times in PBS. Slides were mounted using gelvatol (23 g poly(vinyl alcohol) 2000, $50 \mathrm{ml}$ glycerol, $0.1 \%$ sodium azide to $100 \mathrm{ml}$ PBS) and viewed under a fluorescence microscope (Olympus Provis Malvern, NY, USA) or a confocal scanning fluorescence microscope (Olympus Fluoview).

\section{Riboprobe Preparation and In Situ Hybridization for Mouse SPRR2A}

A $144 \mathrm{bp}$ fragment of mouse SPRR2A cDNA (GenBank accession no. NM011468) was amplified by PCR using primers (5'-CCTTGTCCTCCCCAAGCG-3' and $5^{\prime}$-AGGGCATGTTGACTGCCAT- ${ }^{\prime}$ ) from primary cultured mouse BEC cDNA. The PCR product was then cloned into the pGEM-T vector (Promega, 
Madison, WI, USA) that contains the priming sites of SP6 and T7 transcriptional factors, which was confirmed by DNA sequencing. The pGEM-T vector was linearized with restriction enzymes that cut the multiple cloning site in two orientations, and this served as a template for in vitro transcription of antisense or sense (negative control) riboprobes, using the AmpliScribe T7 and SP6 High Yield Transcription Kits (EPICENTRE, Madison, WI, USA) with digoxigenin-11-UTP (Roche Diagnostics $\mathrm{GmbH}$, Mannheim, Germany), according to the manufacturer's instructions. Tissue specimens were immersion-fixed for $16 \mathrm{~h}$ in $4 \%$ paraformaldehyde/ phosphate-buffered saline and then immersed in $20 \%$ sucrose solution before cryoembedding in TissueTek OCT Compound (Sakura Finetek USA, Torrance, CA, USA). Cryosections of $12 \mu \mathrm{m}$ thickness were collected on Snowcoat X-tra (Surgpath, Richmond, IL, USA). Sections were rehydrated, digested with proteinase $\mathrm{K}(1 \mu \mathrm{g} / \mathrm{ml})$, and then fixed in $4 \%$ formaldehyde in PBS. Acetylation was carried out in $0.1 \mathrm{M}$ triethanolamine in $0.25 \%$ acetic anhydride for $10 \mathrm{~min}$. Slides were hybridized at $50^{\circ} \mathrm{C}$ for $16 \mathrm{~h}$ in $18 \mu \mathrm{l}$ of hybridization buffer containing $50 \%$ formamide, $5 \times$ SSC $(750 \mathrm{mM} \mathrm{NaCl}$, $75 \mathrm{mM}$ sodium citrate $(\mathrm{pH} 7.0)), 5 \times$ denhardts, $250 \mu \mathrm{g} / \mathrm{ml}$ Bakers yeast RNA, $500 \mu \mathrm{g} / \mathrm{ml}$ denatured salmon sperm DNA, and $1 \mu \mathrm{g} / \mathrm{ml}$ DIG-labeled RNA probe. The posthybridization washes were as follows: $3 \mathrm{~min}$ in $5 \times \mathrm{SSC}$ at $50^{\circ} \mathrm{C} ; 30 \mathrm{~min}$ in $50 \%$ formamide and $2 \times \mathrm{SSC}$ at $50^{\circ} \mathrm{C} ; 20 \mathrm{~min}$ in $2 \times \mathrm{SSC}$ at $50^{\circ} \mathrm{C}$; and twice at $50^{\circ} \mathrm{C}$ for $20 \mathrm{~min}$ in $0.2 \times$ SSC. After washing and blocking by DIG Wash and Block Buffer Set (Roche Diagnostics $\mathrm{GmbH}$ ), sections were incubated with a 1:1000 dilution of alkaline phosphatase-conjugated anti-DIG antibody (sheep polyclonal, Fab fragments; Roche Diagnostics $\mathrm{GmbH}$ ) for $30 \mathrm{~min}$ at room temperature. After washing in washing buffer, sections were incubated in $100 \mu \mathrm{l}$ of detection buffer containing nitroblue tetrazolium chloride and 5-bromo-4-chloro-3-indolyl phosphate (1:50 diluted, Roche Diagnostics $\mathrm{GmbH}$ ), and levamisole (Sigma-Aldrich, St Louis, MO, USA) for $16 \mathrm{~h}$ at room temperature. Finally, the color reaction was stopped by washing the sections for $3 \mathrm{~min}$ in $10 \mathrm{mM}$ Tris (pH 8) and $1 \mathrm{mM}$ EDTA. The sections were not counterstained. In situ hybridization was performed three times using both antisense and sense probes to confirm the results.

\section{Statistical Analysis}

The values shown for the various tests are the mean \pm s.d. of three to five representative experiments. The Student's $t$-test was used to compare two groups. One-factor ANOVA was used to detect significant intergroup differences, in which case individual study groups were compared using Fisher's protected least significant difference test. A $P$-value of less than 0.05 was considered to be statistically significant.

\section{Results}

Oligonucleotide Array Analysis of IL-6 ${ }^{+/+}$and IL-6 ${ }^{-/}$ Mouse BEC and Confirmation by Real-Time RT-PCR

IL- $6^{+/+}$and IL- ${ }^{-1-}$ mouse BEC were cultured, in vitro, in a medium that contains forskolin, which stimulates IL- 6 production only by IL- $6^{+1+}$ BEC. ${ }^{28}$ Since IL-6 ${ }^{-1-}$ BEC cannot produce IL-6, this medium accentuates IL-6-related differences between IL- $6^{+/+}$ and IL- $^{-1-}{ }^{-1 E C}{ }^{28}$ The results of gene expression patterns under these conditions were compared using an oligonucleotide array analysis containing 12655 cDNA species (U74A ver.2 array, Affymetrix) (Table 2). Expression of SPRR2A was the highest

Table 2 Top 10 upregulated genes in IL- $6^{+/+}$compared with IL- $6^{-/-}$BEC, and other EDC genes

\begin{tabular}{|c|c|c|c|c|c|}
\hline No. & Genbank \# & Gene & $\begin{array}{c}\text { Expression level } \\
(W T / K O)\end{array}$ & $\begin{array}{l}\text { Fold } \\
\text { change }\end{array}$ & Function \\
\hline 1 & AJ005567 & Small proline-rich protein 2I & $545 / 10$ & 54.5 & EDC gene \\
\hline 2 & AF039663 & AC133 antigen homologue & $205 / 13.5$ & 15.2 & Cell antigen \\
\hline 3 & AJ005563 & Small proline-rich protein $2 \mathrm{E}$ & $805 / 75$ & 10.7 & EDC gene \\
\hline 4 & AJ005560 & Small proline-rich protein $2 B$ & $1294 / 121$ & 10.7 & EDC gene \\
\hline 5 & AJ005559 & Small proline-rich protein $2 \mathrm{~A}$ & 1660/204 & 8.1 & EDC gene \\
\hline 6 & J03953 & Glutathione transferase GT9.3 & $379 / 52$ & 7.2 & Cell metabolism \\
\hline 7 & L06047 & Glutathione-S-transferase, alpha 1 & $382 / 64$ & 6.0 & Cell metabolism \\
\hline 8 & D38410 & Trefoil factor 3 , intestinal (TFF3) & $429 / 76$ & 5.6 & Mucosal cytoprotective function \\
\hline 9 & AB003305 & Proteasome beta type subunit 5, pseudogene & $229 / 43$ & 5.3 & Peptide production \\
\hline \multirow[t]{7}{*}{10} & M17327 & Leukemia virus modified polytropic provirus DNA & $473 / 106$ & 4.5 & Endogenous provirus \\
\hline & AF057156 & Small proline-rich protein 1A & $10 / 10$ & 1 & EDC gene \\
\hline & X91825 & Small proline-rich protein $1 \mathrm{~B}$ & $10 / 10$ & 1 & EDC gene \\
\hline & Y09227 & Small proline-rich protein 3 & $10 / 10$ & 1 & EDC gene \\
\hline & L28819 & Involucrin & $10 / 10$ & 1 & EDC gene \\
\hline & U09189 & Loricrin & $34 / 22$ & 1.5 & EDC gene \\
\hline & M55154 & Transglutaminase & $17 / 15$ & 1.1 & EDC gene \\
\hline
\end{tabular}

These results are representative of two separate experiments. The non-coordinately upregulated Sprr2 genes are shown in bold type. 
among the four SPRR2-subfamily genes, as determined by high density oligonucleotide array analysis (Table 2) and confirmed by semiquantitative RT-PCR. SPRR1 and SPRR3 failed to show differential regulation under these circumstances (Table 2), which suggested noncoordinate regulation
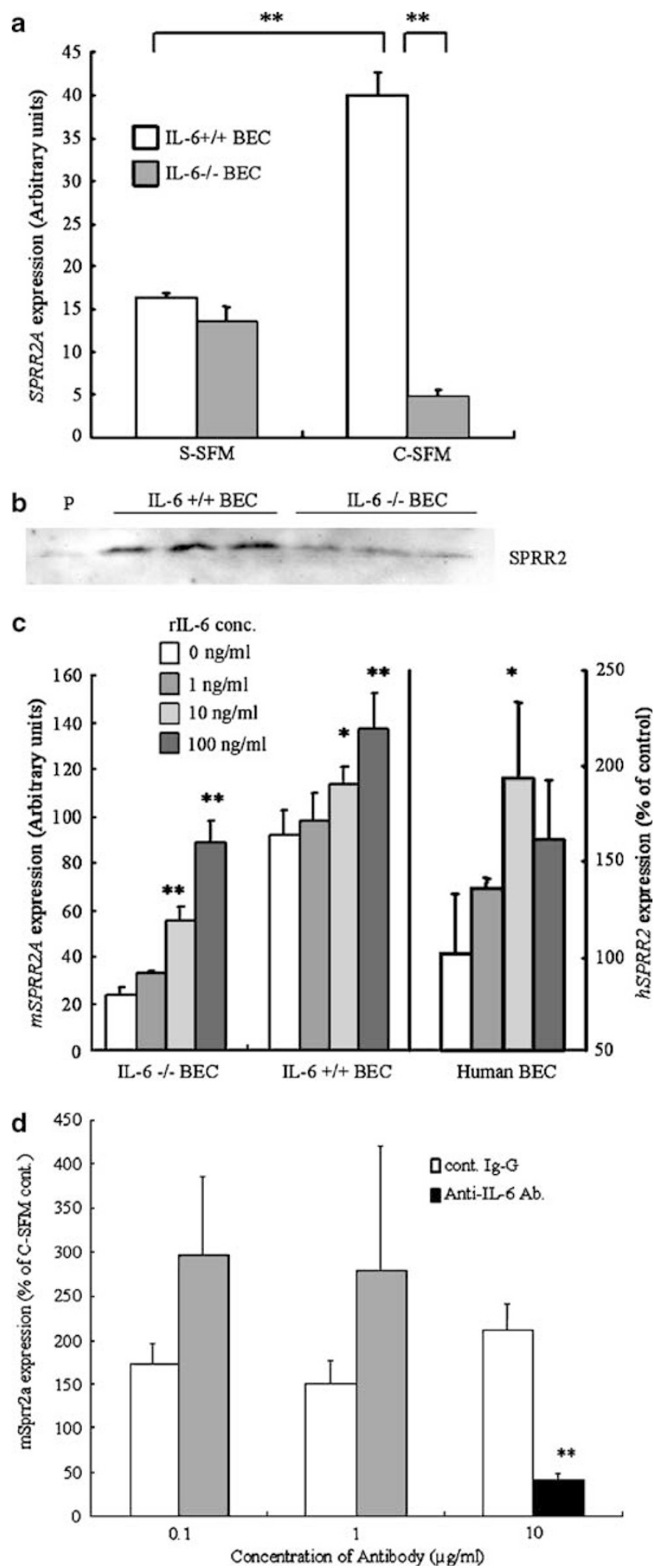

of SPRR2A expression. Therefore, we focused on SPRR2A mRNA and protein expression of mouse BEC in further experiments.

SYBR Green quantitative real-time RT-PCR analysis for SPRR2A expression confirmed the array analysis: when cultured under conditions that stimulate IL-6 production, IL- $6^{+/+}$BEC produce significantly more SPRR2A mRNA and protein than IL-6 ${ }^{-1-}$ BEC (Figure 1a and b). Also, there was a direct correlation between SPRR2A mRNA and protein levels (Figure 1a and b). BEC SPRR2 expression in $\mathrm{IL}^{-} 6^{+/+}$and IL-6 ${ }^{-/-}$mouse BEC and human BEC was augmented with exogenous IL-6 (Figure 1c). The high levels of SPRR2A expression in IL-6 ${ }^{+/+}$BEC were blocked by adding anti-IL-6 antibody (Figure 1d).

\section{IL-6/gp130/STAT3 Signaling Stimulates Noncoordinate Upregulation of BEC SPRR2 mRNA and Protein Expression}

IL-6 cytokine family members activate two intracellular signaling pathways: STAT3 and Src-homology tyrosine phosphatase 2 (SHP)-Ras-MAPK pathways, and there is reciprocal negative regulation between them. ${ }^{33}$ If BEC SPRR2A expression is related primarily to STAT3 signaling, then blocking STAT3 signaling should inhibit BEC SPRR2A expression, whereas blocking MAPK signaling should increase SPRR2A expression. The converse should be observed if MAPK signaling is primarily responsible for BEC SPRR2A expression.

An adenoviral vector encoding a dominant-negative form of STAT3 (AdSTAT3-DN) was used to determine the effect of blocking STAT3 signaling (Figures 2a and b). PD98059, a specific inhibitor of MAPK kinase 1 (MAPKK1) activation and p44/p42 MAPK activity, was used to block MAPK activity (Figure 2C). IL-6 $6^{+/+}$BEC infected for 2 days with either AdSTAT3-DN or the control vector AdGFP were then treated with or without recombinant IL-6 (rIL-6) for $24 \mathrm{~h}$ in an effort to maximize SPRR2A expression. When $\mathrm{IL}^{-6}{ }^{+/+}$BEC were transfected with AdSTAT3-DN and treated with IL-6, the

Figure 1 IL-6/STAT3 signaling upregulates SPRR2 mRNA and protein expression in primary BEC cultures. (a) When kept in SSFM, a medium that does not stimulate BEC IL-6 production, SPRR $2 A$ expression in IL- $6^{+/+}$and IL-6 ${ }^{-1-}$ BEC were the same. However, when the BEC were cultured in C-SFM, a medium that stimulates endogenous IL-6 production, SPRR2A expression was significantly higher in IL-6 ${ }^{+/+}$BEC $\left({ }^{*} P<0.01\right)$. (b) SPRR2A protein expression in IL-6 $6^{+/+}$and IL-6 $6^{-/-}$BEC after $72 \mathrm{~h}$ in C-SFM directly correlated with mRNA levels as determined by Western blot analysis. The SPRR2A protein band is present at approximately $14 \mathrm{kDa}$; mouse skin was used as a positive control (P). (c) Effect of exogenous rIL-6 on SPRR2 expression by IL-6 ${ }^{-/-}$BEC, IL$6^{+1+}$ BEC, and human BEC $\left({ }^{*} P<0.05,{ }^{*} P<0.01\right.$ vs control). (d) Treatment of IL-6 ${ }^{+/+}$BEC kept in C-SFM with anti-IL-6 antibody for $48 \mathrm{~h}$ resulted in decreased SPRR $2 A$ mRNA production, as determined by real-time PCR $\left({ }^{*} P<0.03\right)$. 

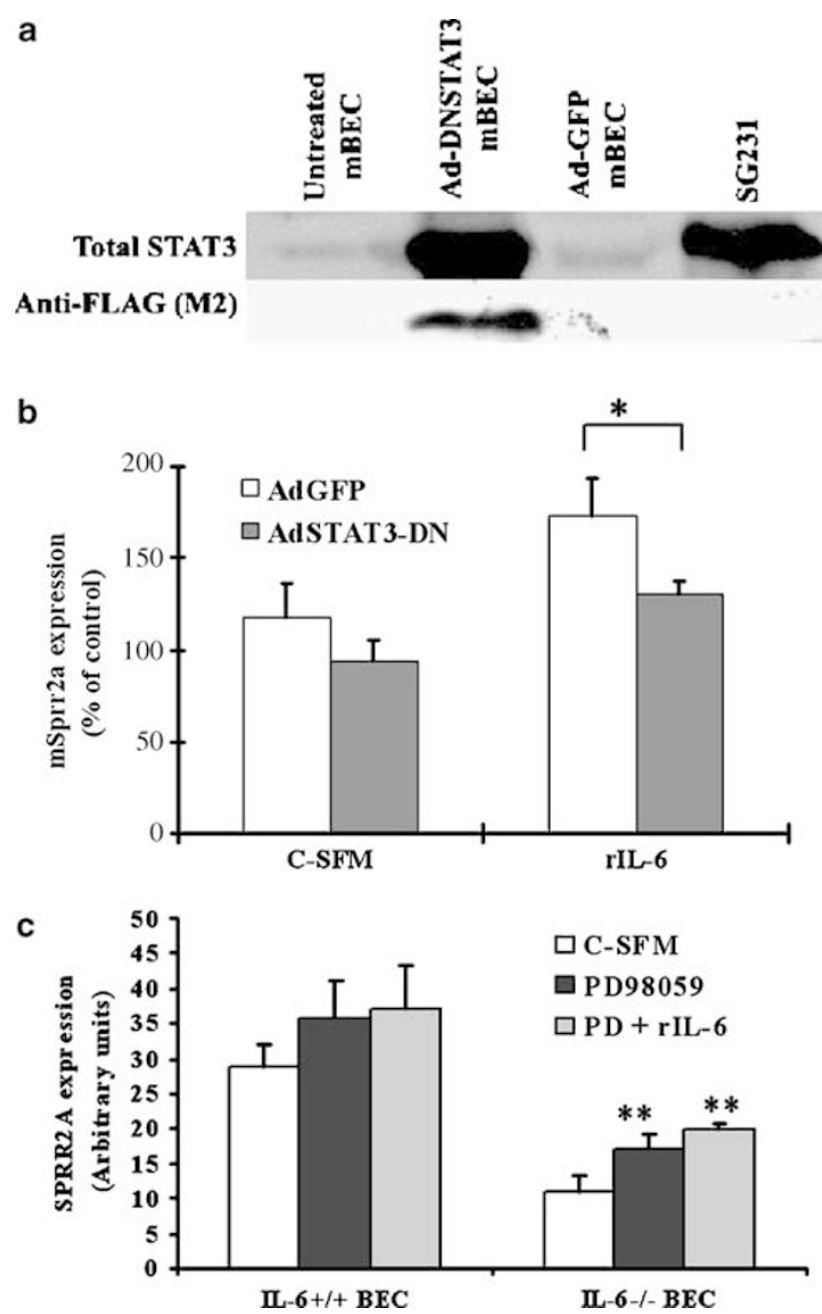

Figure 2 BEC were transfected for 2 days with either the adenoviral study vector, AdSTAT3-DN, or the adenoviral control vector, AdGFP, and then incubated with or without rIL-6 (10 ng/ $\mathrm{ml}$ ) for $24 \mathrm{~h}$. (a) Western blotting for total STAT3 levels shows significantly increased STAT3 levels compared to untreated mouse BEC and mouse BEC treated with the AdGFP control vector. In addition, the anti-FLAG (M2) marker used to tag the DN-STAT3 was detectable only in the mouse BEC transfected with AdSTAT3-DN. A human cholangiocarcinoma cell line, SG231 that shows constitutive STAT3 activity was used as a positive control. (b) SPRR2A expression was significantly lower in IL-6 ${ }^{+/+}$BEC transfected with AdSTAT3-DN than with AdGFP, especially when the BEC were simultaneously challenged with rIL-6 $(10 \mathrm{ng} / \mathrm{ml})$ for $24 \mathrm{~h}\left({ }^{*} P=0.05\right)$. (c) Treatment with the MAPK inhibitor alone, PD98059 $(25 \mu \mathrm{M})$, or a combination of PD98059 and rIL-6 (10 ng/ $\mathrm{ml}$ ) for $24 \mathrm{~h}$ increased SPRR2A expression in mouse IL- $6^{+1+}$ and IL- $6^{-/-}$BEC $(* * P<0.01$ vs control).

expression of SPRR2A was significantly lower than BEC transfected with the control vector (Figure $2 b$ ). In contrast, blocking MAPK activity significantly upregulated SPRR2A expression in $\mathrm{IL}^{-6^{-/}}$BEC (Figure 2c). In addition, the combination of rIL-6 and PD98059 treatment further increased SPRR2A expression in IL- $6^{-1-}$ BEC. IL- $6^{+/+}$BEC also showed upregulation of SPRR2A expression when treated with PD98059 or with combination of rIL-6 and PD98059 (Figure 2c).
Since SPRR2 is a member of the EDC and contributes to the formation of the CE, BEC expression of SPRR2 might be related to squamous metaplasia or formation of a CE because the biliary tree can undergo squamous metaplasia. We therefore examined expression of other EDC genes such as transglutaminase, loricrin, and involcrin mRNAs that are required for SPRR to contribute to formation of a CE. ${ }^{34}$ Oligonucleotide array analysis showed that these three genes were expressed in mouse BEC, but in contrast to SPRR2, there was no differential regulation between IL- $6^{-/-}$and IL- $6^{+/+}$BEC (Table 2). Thus, isolated upregulation of BEC SPRR2 under these circumstances represents an example of noncoordinate or preferential upregulation of SPRR2 gene expression that putatively enables selective modification of specific epithelial barriers. ${ }^{2,8}$

\section{SPRR2 mRNA Expression Increases after BDL Preferentially in IL-6 ${ }^{+/+}$Mice, Localizes Exclusively the BEC, and is not Related to Squamous Metaplasia or Formation of a Cornified Cell Envelope}

If $S P R R 2 A$ expression in the biliary tree is related to selective modification of BEC barrier function, BDL should cause alterations in hepatic expression of $S P R R 2$, and expression should be localized to BEC. Therefore, IL- $6^{-/-}$and IL- $6^{+/+}$mice were subjected to BDL or sham operation (controls) and killed at 0 and $4 \mathrm{~h}$, and 1,3 , and 7 days and 6,7 , and 12 weeks later. During the first week after BDL or sham operation, the 'biliary tree' was separated from the 'hepatocyte' fraction or the remainder of the hepatic parenchyma (see Materials and methods). Bile duct ligation blocks the normal flow of bile, and increases intraluminal pressure. ${ }^{35}$ This maneuver stresses and damages the BEC and biliary barrier, which in turn triggers an adaptive response of the biliary tree. ${ }^{36}$

The normally low levels of SPRR2A expression in the biliary tree of IL- $6^{+/+}$and IL- $6^{-1-}$ mice showed a dramatic 14-fold increase by 3 days after BDL in the IL-6 ${ }^{+/+}$mice (Figure 3a). SPRR2A levels also increased at 3 days after BDL in the $\mathrm{IL}^{-6^{-1-}}$ mice, but the increase was significantly lower than that seen in the IL-6 ${ }^{+/+}$mice. SPRR $2 A$ expression was not upregulated in the biliary tree after sham operation and was absent from the hepatocyte (or parenchymal cell) fraction at all time points after BDL. In situ hybridization confirmed these results by showing that SPRR2A mRNA expression localized exclusively to the BEC of large and small bile ducts, but not to hepatocytes or stromal cells (Figure 3c).

More than 1 week after BDL, it was not possible to reliably separate the 'biliary tree' from the 'hepatocyte' fraction because of fibrosis. Therefore, SPRR2A expression was evaluated in whole liver (Figure $3 \mathrm{~b}$ ). SPRR2A expression reached a plateau by 7 weeks after BDL and remained at that level until the end of the experiment at 12 weeks, when IL- $6^{+/+}$mouse 
a

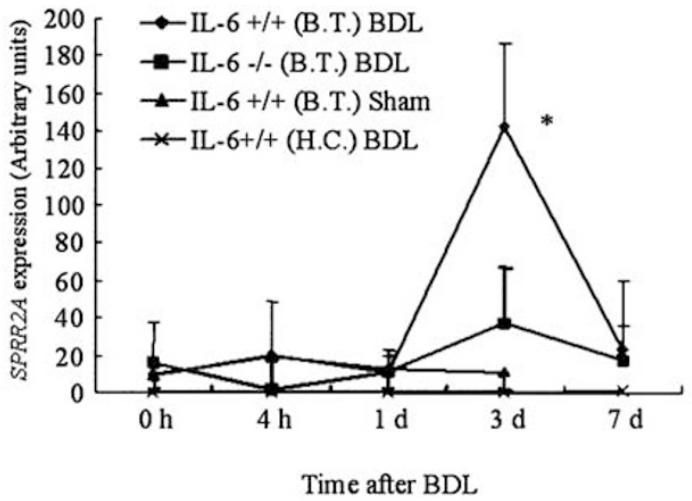

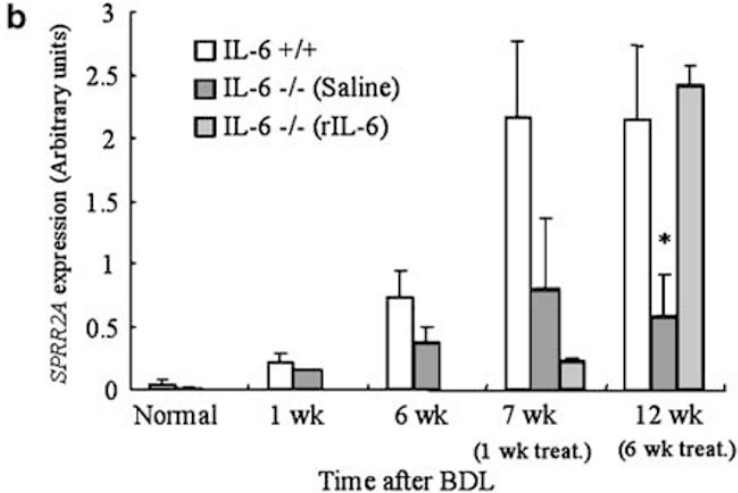

Time after BDI

C

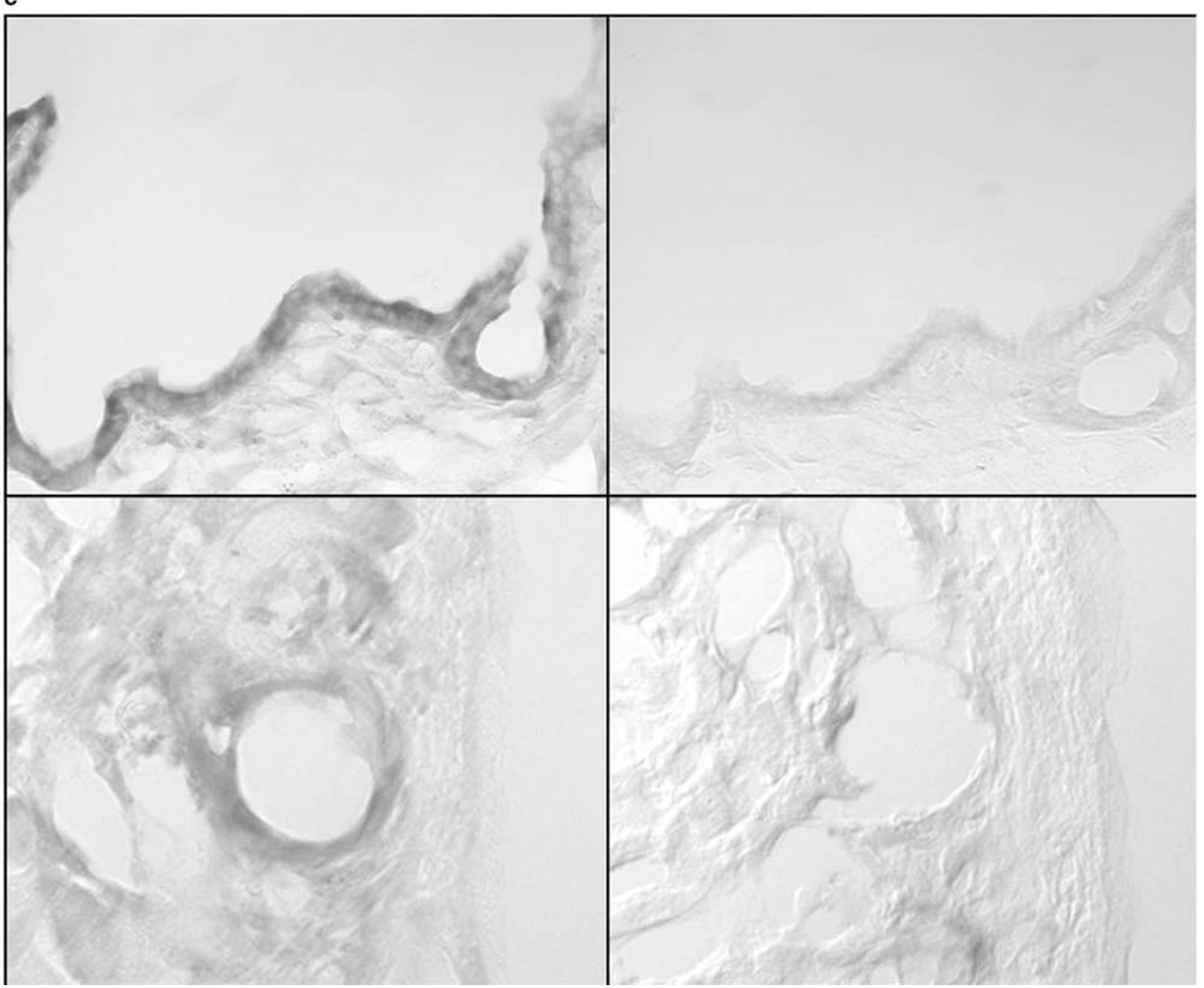

Figure 3 BDL upregulates SPRR2A expression in mouse liver and expression is limited to the BEC. (a) Time course of SPRR2A expression in the IL- $6^{+/+}$and IL- $6^{-1-}$ 'biliary tree' fraction (BT) and IL- $6^{+/+}$'hepatocyte' (HC) fraction during the first week after BDL or sham operation $\left({ }^{*} P<0.05\right.$, vs the other three). (b) Time course of SPRR2A expression in IL- $6^{+/+}$and IL-6 ${ }^{-/-}$whole liver up to 12 weeks after BDL. IL- $6^{-1-}$ mice were treated daily with either saline (controls) or rIL-6 starting at 6 weeks after BDL and continued for 1 or 6 weeks ( ${ }^{*} P<0.05$, vs the other two). (c) In situ hybridization for mouse SPRR2A mRNA at 5 days after BDL in IL- ${ }^{+/+}$mice showed that expression was limited to BEC lining larger bile ducts (antisense probe in upper left panel) and small bile ductules (antisense probe in lower left panel). In contrast, the negative control (hybridization with the sense probe) showed no signal (upper and lower right panels) on serial sections of the same bile ducts. 
liver showed a 40-fold increase in SPRR2A expression compared to baseline levels. In contrast, IL-6 ${ }^{-1-}$ livers showed only a modest increase of SPRR2A expression after BDL compared to $\mathrm{IL}^{-6}{ }^{+/+}$mice liver leading to a significant difference in SPRR2A expression at 12 weeks after BDL. Daily injection of exogenous rIL-6 to IL- $6^{-/-}$mice, starting at 6 weeks and continued for 1 or 6 weeks, significantly increased the low level of SPRR $2 A$ expression in IL- $6^{-/-}$mice livers at 12 weeks (Figure $3 \mathrm{~b}$ ).

Changes in transglutaminase expression (required for SPRR utilization in CE formation) and histologic examination for squamous metaplasia were undertaken to exclude the possibility that the increased SPRR2 expression after BDL was related to squamous metaplasia or formation of a CE. There was no change of transglutaminase expression in the mouse bile duct tree after BDL (by real-time PCR) and no histopathologic evidence of squamous metaplasia at any time after BDL (data not shown).

\section{Evidence of Impaired Biliary Tree Integrity in IL-6 ${ }^{-/-}$ Mice after Long-Term BDL}

In previous studies by our group there were signs of impaired biliary tract integrity in IL- $6^{-1-}$ mice after BDL. ${ }^{18,25}$ These include more bile infarcts and higher liver injury tests early after BDL, ${ }^{18}$ and higher direct serum bilirubin, darker bile color, and hepatic decompensation in the $\mathrm{IL}^{-6^{-1}}$ mice at 12 weeks after BDL. ${ }^{25}$ The concentration of bilirubin pigments determines the color of bile in an obstructed biliary tree. ${ }^{37-39}$ Dark or 'black' bile indicates a high concentration of bilirubin pigments and is associated with decreased intraluminal pressure in the biliary tree ${ }^{39}$ compared to 'white' bile that is associated with higher intraluminal pressures ${ }^{39}$ and a low concentration of bilirubin pigments. ${ }^{39,40}$ If the barrier function of the biliary tree is impaired in IL- $6^{-/}$mice, then the following findings would be expected in the obstructed biliary tree at 12 weeks after BDL: (1) less dilated intrahepatic bile ducts (less pressure ${ }^{35}$ ); (2) decreased bile volume; ${ }^{35}$ and (3) darker bile color. ${ }^{39}$

Morphometric analysis of mouse liver sections taken from the same location in the livers (see Materials and methods) at 12 weeks after BDL showed that the average shortest diameter of the largest intrahepatic bile ducts was significantly smaller in IL- $6^{-/-}$mice by $49 \%(P=0.0013)$ when compared to IL-6 ${ }^{+/+}$mice $(25.3 \pm 16.4$ and $49.4 \pm 26 \mu \mathrm{m}$ for IL- $6^{-1-}$ and IL- $6^{+/+}$, respectively) (Figure 4a). This observation was supported by the volume of bile collected in the obstructed biliary tree of $\mathrm{IL}_{-} 6^{+/+}$mice $(1.9 \pm 0.5 \mathrm{ml})$, which was significantly greater than that collected from the IL-6 $^{-1-}$ mice $(0.9 \pm 0.4 \mathrm{ml} ; P<0.03)$. Finally, direct comparison of the bile color in the IL- $6^{-/-}$and the IL-6 $6^{+/+}$mice at 12 weeks after bile duct ligation is shown in the 'bile blot' in Figures $4 \mathrm{~b}$ and c. The bile from the obstructed biliary tree of IL- $6^{-/-}$mice at 12 weeks after bile duct ligation was significantly darker than the bile from IL-6 ${ }^{+/+}$mice (Figure 4c; $P<0.04)$.

\section{Localization of SPRR2 Protein in Mouse and Human Liver Tissues}

To determine whether BEC SPRR2 expression can be localized in diseased mouse and human liver tissue, we stained sections for SPRR2 protein and BECspecific cytokeratins AE1/AE3. Liver tissue from IL$6^{+/+}$and IL- $6^{-1-}$ mice at 12 weeks after BDL (Figure 5) and human liver tissue affected by PBC (Figure 6) were chosen for analysis. PBC was chosen as a disease model because of increased intrahepatic expression of IL- $6,{ }^{22}$ bile duct damage, and a BEC reaction to injury. ${ }^{22}$

The results showed that SPRR2 protein localized exclusively to the BEC in both mouse and human liver tissues (Figures 5 and 6), consistent with the mRNA results. In mouse and human samples, SPRR2 localized primarily to a region immediately subjacent to apical cytoplasmic membrane of BEC lining normal-appearing septal bile ducts (Figures 5 and 6); the same bile ducts coexpressed cytokeratin (Figures 5 and 6). In contrast, SPRR2 assumed a perinuclear and diffuse cytoplasmic localization in cholangioles embedded in the fibrous stroma (Figure 6b, d, and f). Cholangiolar Sprr2 staining in the mice was weaker than cholangiolar staining in the human samples; however, Sprr2 staining in the larger bile ducts was of similar intensity.

\section{Discussion}

Virtually any biliary tree insult, such as obstruction, ${ }^{17-19}$ infection, ${ }^{19,20}$ or immunologic damage ${ }^{21-23}$ triggers increased BEC expression of IL- $6 .{ }^{24}$ Since IL$6^{-1-}$ mice show impaired barrier function in the biliary tree after bile duct ligation, we sought to determine the (patho-) physiologic consequences of IL-6 production at sites of biliary tract injury. To accomplish this task, we first employed gene expression microarray analysis in a simple experiment that compared $\mathrm{IL}_{-6}{ }^{+/+}$and $\mathrm{IL}^{-6}{ }^{-/-}$BEC, in vitro, under conditions that stimulate IL-6 production by the BEC. The goals were to identify candidate genes that are: (1) expressed in BEC, (2) regulated by IL-6 signaling, and (3) possibly contribute to barrier function in the biliary tree. One of the most promising candidate genes was SPRR2, which is known to contribute to barrier function in the skin. Therefore, we set out to conduct a more detailed study of the regulation of BEC SPRR2A expression, in vitro, followed by detailed in vivo studies after BDL, a maneuver that stresses the biliary barrier. The expectation was that BDL would increase BEC SPRR2A expression in the $\mathrm{IL}^{-6^{+/+}}$ mice, but not in IL- $^{-/-}$mice. 


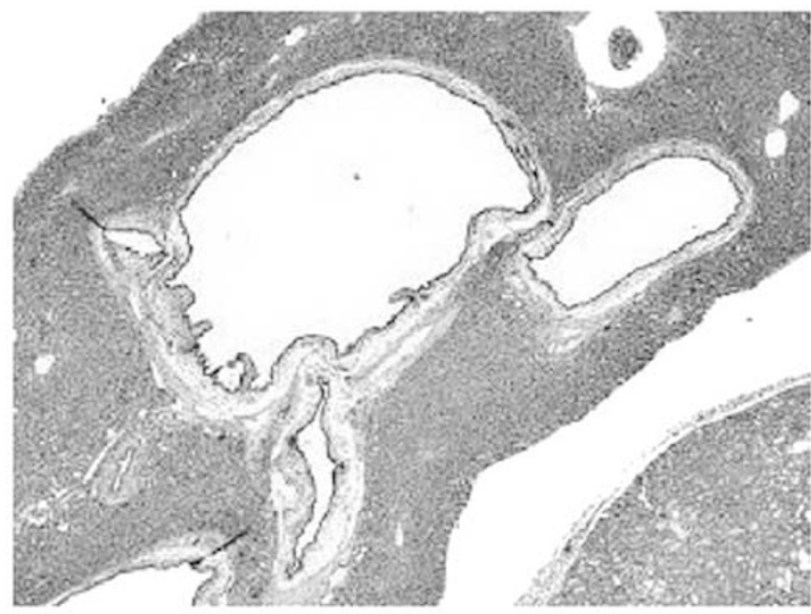

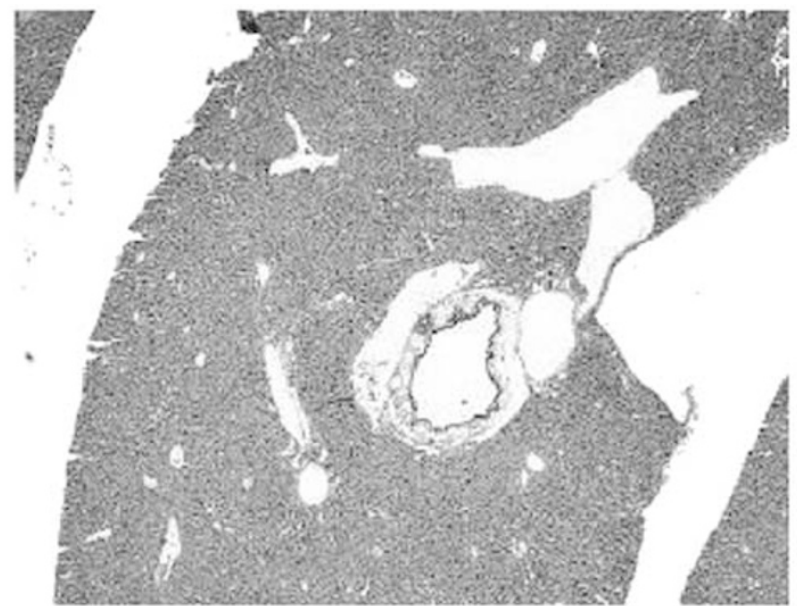

b IL $-6+1+$

\section{IL-6-/-}
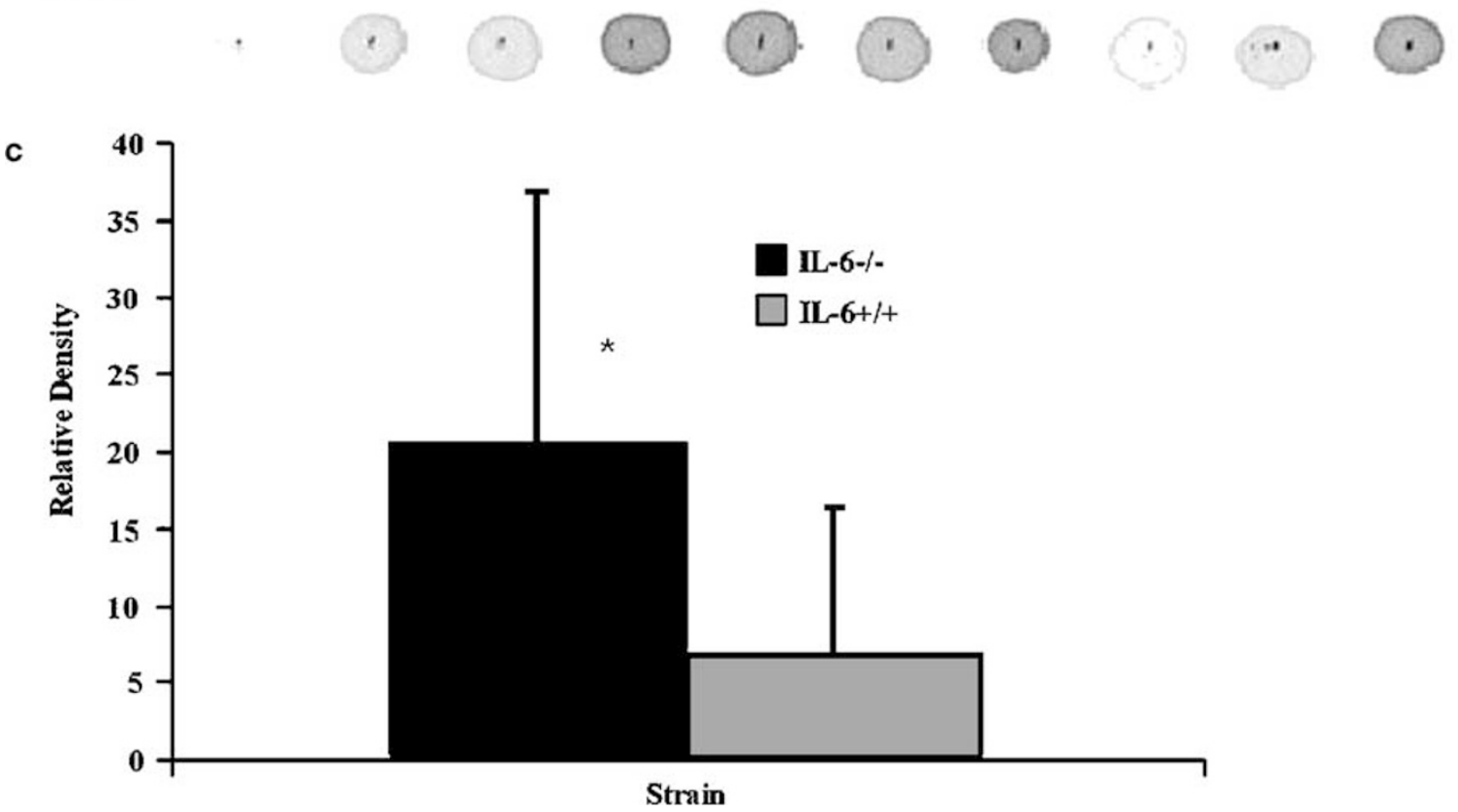

Figure 4 (a) Morphometric analysis of the diameter of the obstructed bile ducts at 12 weeks after BDL showed that IL-6 $6^{+/+}$bile ducts (left panel) were significantly larger than the IL- $6^{-/-}$bile ducts (right panel), indicative of a lower volume in the IL- $6^{-/-}$biliary tree (see text). The photomicrographs were taken at the same magnification. (b) Blotting of bile obtained from the obstructed biliary tree of ten IL-6 ${ }^{-\prime}$ and IL- $6^{+1+}$ mice at 12 weeks after BDL shows the dramatic difference in the color of bile. Note the clear or 'white bile' appearance of 9/10 IL- $6^{+/+}$mice. The majority of IL- $6^{-/-}$mice showed 'black bile', indicative of the presence of bile pigments, and consequently lower intraluminal pressure because of ongoing bile leakage from the 'obstructed' biliary tree. (c) Densitometry tracing of the bile blot showed that the IL- $6^{-/-}$bile was significantly darker than the IL- $6^{+/+}$bile at 12 weeks after BDL $(P<0.04)$.

The IL-6 family of cytokines activates two distinct intracellular signaling pathways, STAT3 and Srchomology tyrosine phosphatase 2 (SHP)-Ras-MAPK pathways, and there is reciprocal negative regulation between them. ${ }^{33}$ Strong STAT3 signaling diminishes the MAPK pathway, and vice versa. Therefore, studies conducted in vitro, show unequi- vocally that STAT3 signaling is an important stimulator of noncoordinate BEC SPRR2 expression, a conclusion further substantiated by sequence analysis of the promoter region of mouse SPRR2A genes (http://www.cbrc.jp/research/db/TFSEARCH. html). It reveals two putative STAT1/3 binding sites at -626 and -362 and a putative AP-1 binding site 

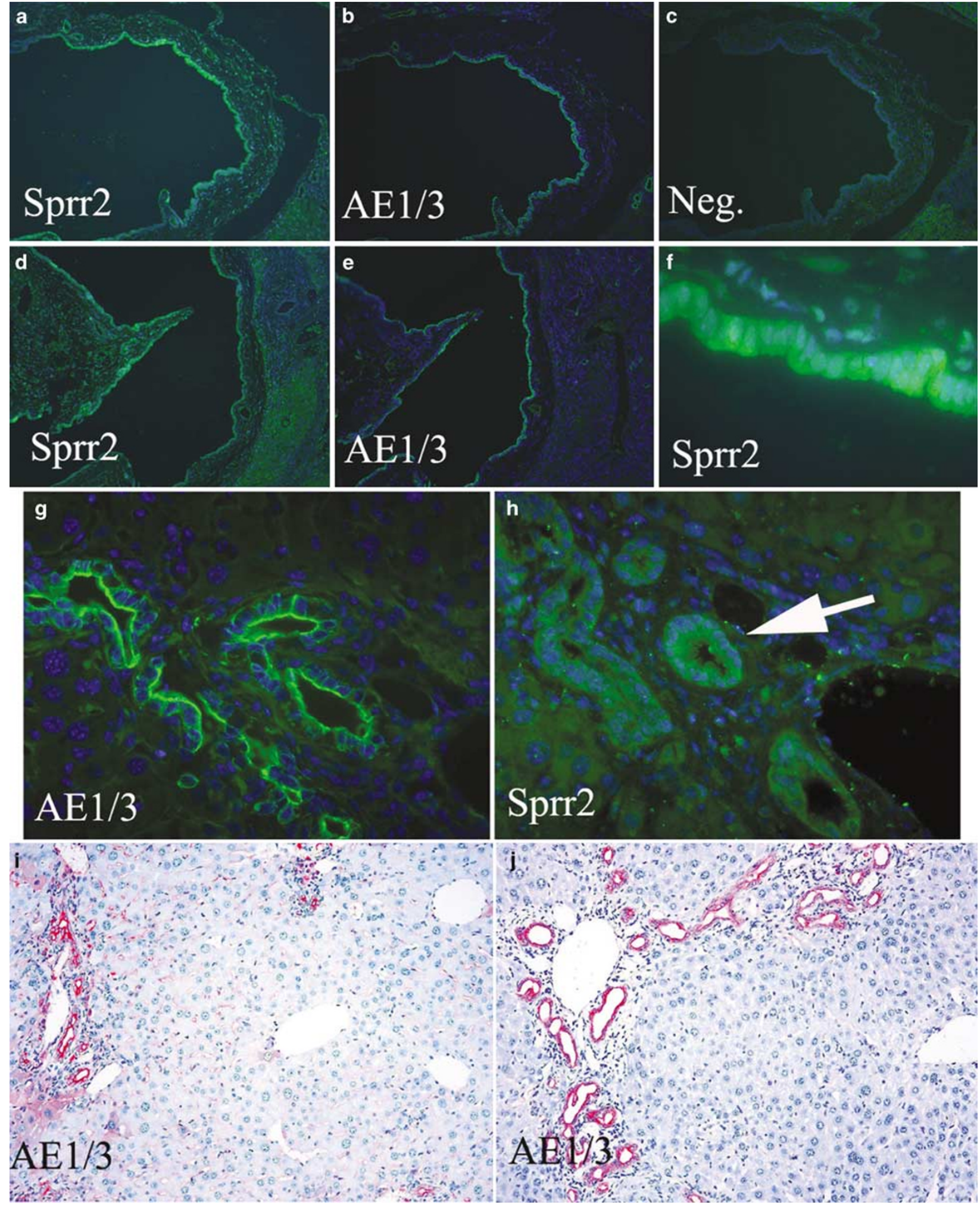

Figure 5 Immunofluorescence and immunoperoxidase staining of IL- $6^{+/+}$and IL- $6^{-/-}$mouse liver at 12 weeks after BDL. (a-c) Large bile duct from the liver of an IL- $6^{+/+}$mouse at 12 weeks after BDL stained with anti-Sprr2 (a), anti-cytokeratin AE1/3 (b), and negative control (c). (d-e) Large bile duct from the liver of an IL-6 ${ }^{-1}$ mouse at 12 weeks after BDL stained with anti-Sprr2 (d) and anti-cytokeratin AE1/3 (e). (f) High magnification of the large bile duct shown in (a) taken from a IL-6 ${ }^{+/+}$mouse. Note the intense cytoplasmic staining with slight apical accentuation. (g, h) High magnification of cholangioles from a IL-6 ${ }^{+/+}$mouse at 12 weeks after BDL showing serial sections stained for cytokeratin AE1/3 (g) and Sprr2 (h). The bottom panel (i, j) stained with cytokeratin AE1/3 shows that the ductular reaction was less prominent in IL- $6^{+/+}$mice (i) compared to IL- $6^{-/-}$mice at 12 weeks after BDL (j), as previously reported by quantitative morphometry comparing the volume proportions of BEC. ${ }^{25}$ 

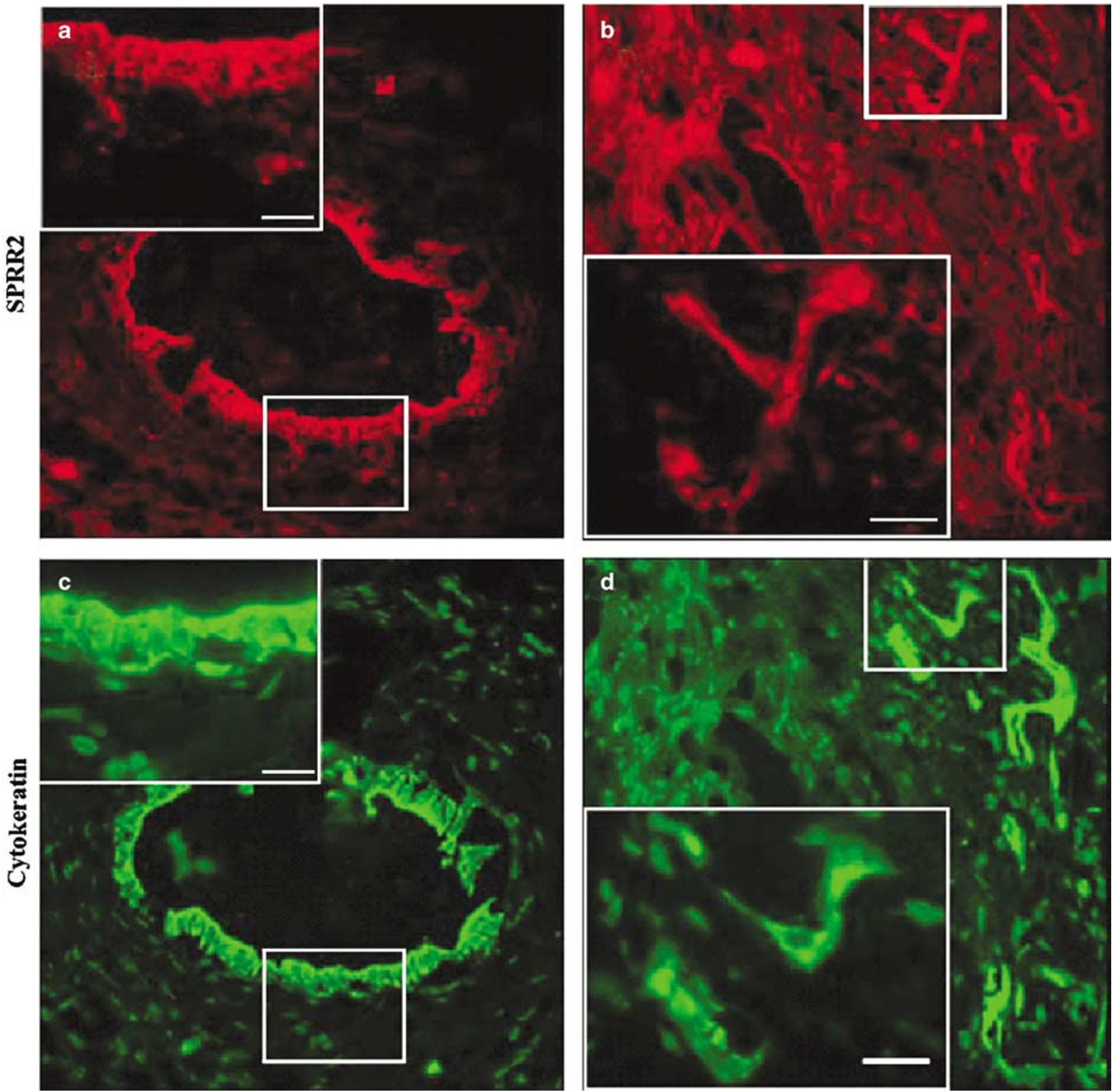

Figure 6 Fluorescent immunostaining on the same or serial sections of diseased human livers with primary biliary cirrhosis was used to localize SPRR2 (red, a and b) and AE1/AE3 cytokeratin (green, $\mathbf{c}$ and $\mathbf{d}$ ) in medium-sized bile ducts (a and $\mathbf{c}$ ) and cholangioles (b and d) in the periductal stroma. Double labeling for SPRR2 (red) and AE1/AE3 cytokeratin (green) was used to colocalize the signals; cells expressing both signals appear yellow (yellow, e and f). Hoechst-positive nuclei are shown in blue in (e) and (f). SPRR2A protein localized to both medium-sized bile ducts and to cholangioles, but not to hepatocytes or other stromal cells. (g, h) H\&E-stained section of the larger (g) bile ducts and cholangioles (h).

located at -596 from the transcription starting position. In human SPRR2 genes, there are also conserved kruppel, Ets, and Oct binding sites. ${ }^{3}$ However, the reciprocal negative regulation between MAPK and STAT3 signaling also influences BEC SPRR2 expression, as evidenced by the ability of the MAPK inhibitor, PD98059, to increase BEC SPRR2 expression.

The in vivo studies conducted herein also show that IL-6/gp130/STAT3 signaling is also important in stimulating noncoordinate upregulation of BEC
SPRR2 expression in the biliary tree after BDL. We have previously shown that STAT3 signaling is deficient in the $\mathrm{IL}^{-6}{ }^{-/-}$mice after BDL. ${ }^{25}$ In this study, a deficiency of IL-6/gp130/STAT3 signaling in the IL- $6^{-1-}$ mice was associated with impaired BEC SPRR2A expression. However, other cytokines and BEC growth factors, such as hepatocyte growth factor (HGF), which is not secreted by nonneoplastic BEC and primarily stimulates MAPK signaling ${ }^{41}$ can decrease BEC SPRR2 expression, in vitro (data not shown). 

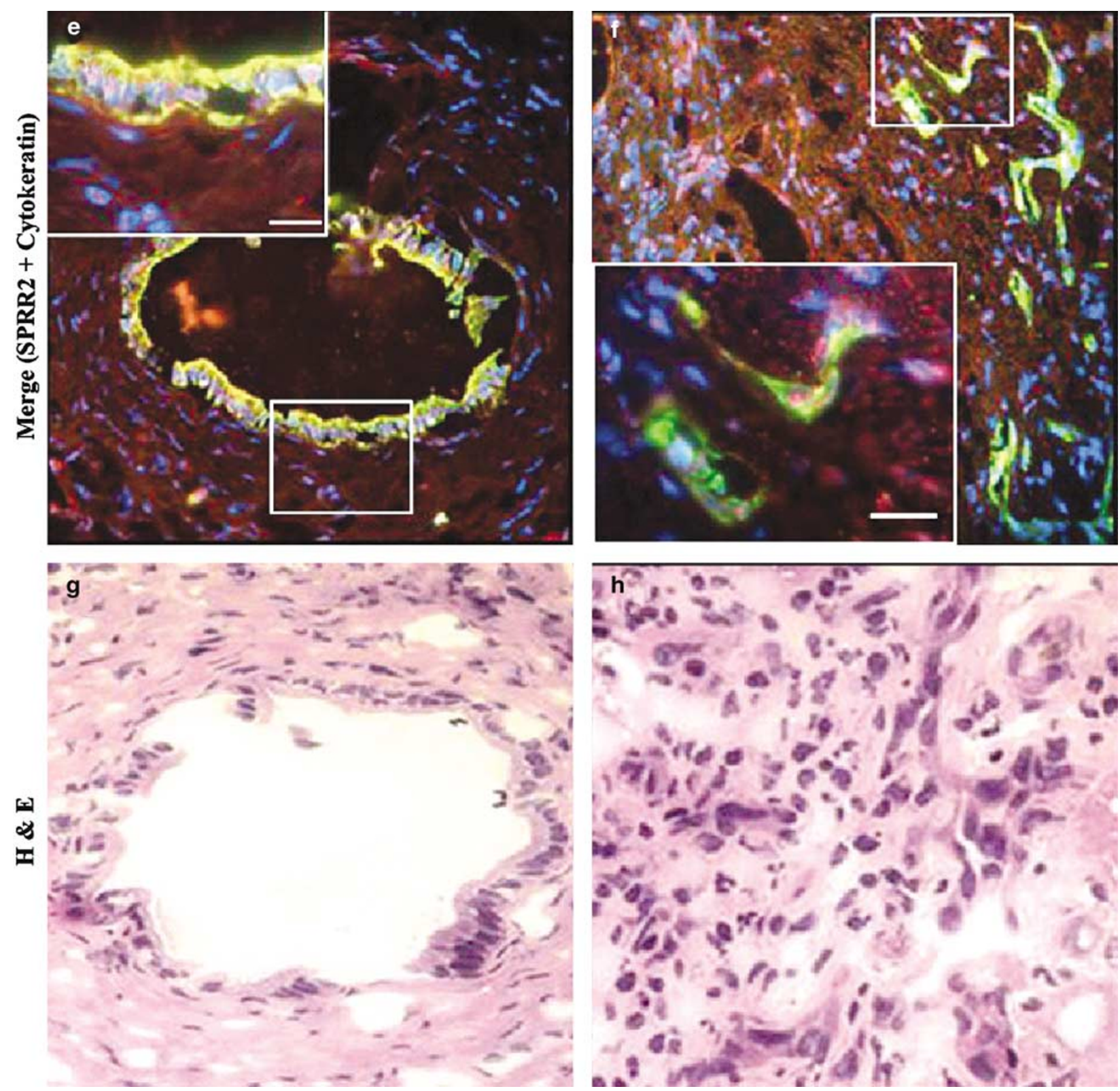

Figure 6 Continued.

Impaired BEC SPRR2 expression in the biliary tree after BDL is associated with impaired barrier function. Previous data from $\mathrm{IL}_{-} 6^{+/+}$and $\mathrm{IL}-6^{-/-}$ mice after $\mathrm{BDL}^{25}$ and evidence generated in the present study support this conclusion. First, the diameter of the largest bile duct in the obstructed biliary tree was smaller in IL-6 ${ }^{-/-}$mice compared to IL- $6^{+1+}$ wild-type controls and contained less bile volume. We were not able to directly measure the intraluminal pressure in the obstructed biliary trees because of their fragility. However, these findings strongly suggest that the biliary tree of $\mathrm{IL}^{-6^{-/}}$mice contained less pressure than the IL- $6^{+/+}$mice, ${ }^{35}$ a conclusion further supported by increased bile infarcts and higher liver injury tests early after
$\mathrm{BDL}^{18}$ when circumferential stresses and wall strains are highest. ${ }^{35}$ Second, the IL-6 ${ }^{-/-}$mice were significantly less able to make 'white' bile, which is devoid of bilirubin and bile salts. ${ }^{40}$ Previous studies on the etiology of 'white bile' have conclusively shown that the intraluminal pressure within a biliary tree containing 'white bile' is significantly higher than the intraluminal pressure within a biliary tree containing 'black bile'; ${ }^{39}$ and 'black bile' contains significantly higher levels of bilirubin and bile salts. ${ }^{40}$

Bilirubin present in the bile is responsible for the dark color and is produced and secreted via pressure-sensitive hepatocyte transport mechanisms. ${ }^{42,43}$ Once pressure exceeds a certain threshold, 
bilirubin secretion decreases dramatically and the residual bile bilirubin trapped within the biliary tree can be reabsorbed by the biliary epithelium. ${ }^{44}$ Therefore, it is not unreasonable to conclude that intraluminal pressures in the $\mathrm{IL}-6^{+/+}$mice reach high enough levels to decrease hepatocyte secretion of bilirubin and the residual bilirubin is resorbed and/or degraded resulting in 'white bile'. In contrast, conjugated bilirubin pigments continue to be secreted into the biliary tree of IL- $6^{-/-}$mice because of lower intraluminal pressures related to the leakage of bile back into the blood because of a barrier defect. This results in significantly higher concentrations of conjugated and delta-bilirubin in the blood of the IL- $6^{-1-}$ mice. ${ }^{25}$

We cannot conclude with certainty that deficient SPRR2 expression is the sole factor responsible for the impaired biliary tree integrity in the IL- $6^{-/-}$ mice. However, it is reasonable to conclude that noncoordinate upregulation of BEC SPRR2 expression in the biliary tree contributes to barrier function, as in other nonsquamous epithelial barriers such as the intestines. ${ }^{10,11}$ Our findings are consistent with the speculation of Cabral et al, ${ }^{2}$ who suggested that noncoordinate upregulation of SPRR genes allows for selective modifications to specific epithelial barriers that are subjected to unique and diverse insults.

Interestingly, the early peak of SPRR2 expression at 3 days after BDL occurs immediately after the peak of circumferential wall stress exerted by the increased intraluminal pressure of BDL. ${ }^{35}$ Conversely, the gradual long-term increase in SPRR2 expression between 3 and 7 weeks, which then reached a plateau directly, correlates with changes in intraluminal pressure within the obstructed biliary tree. ${ }^{35}$

Beyond concluding that BEC SPRR2A contributes to selective modification of the biliary barrier in response to stress, we can only speculate at this juncture on molecular mechanisms. Considering the importance of SPRR2 as a crosslinking protein, it is not unreasonable to suggest that SPRR2 forms bridges between cytoskeletal proteins and membrane proteins in an effort to increase rigidity. ${ }^{2,45}$ However, the different intracellular localization of SPRR2 in BEC lining medium-sized bile ducts (subjacent to the plasma membrane with accentuation at the luminal border) and in cholangioles (perinuclear or more diffusely throughout the cytoplasm), suggests that SPRR2 may have more than one function. Preliminary studies with a BEC cell line stably transfected with a SPRR2A vector produced distinct changes in cell shape and increased ability to migrate (manuscript in preparation). These findings strongly suggest a role for SPRR2 in cell migration and wound healing, a contention further supported by association between impaired wound healing in the $\operatorname{skin}^{46}$ and gastrointestinal $\operatorname{tract}^{47}$ with a deficiency of IL-6/ gp130/STAT3 signaling.

\section{Acknowledgements}

This work was supported by NIH Grants RO 1 DK49615 (AJD) and R43DK60270 (VS). We thank Dr J Park for AdSTAT3-DN, and Dr J Luo for the oligonucleotide array analysis.

\section{References}

1 Marenholz I, Zirra M, Fischer DF, et al. Identification of human epidermal differentiation complex (EDC)encoded genes by subtractive hybridization of entire YACs to a gridded keratinocyte cDNA library. Genome Res 2001;11:341-355.

2 Cabral A, Voskamp P, Cleton-Jansen AM, et al. Structural organization and regulation of the small proline-rich family of cornified envelope precursors suggest a role in adaptive barrier function. J Biol Chem 2001;276:19231-19237.

3 Patel S, Kartasova T, Segre JA. Mouse Sprr locus: a tandem array of coordinately regulated genes. Mamm Genome 2003;14:140-148.

4 Mischke D, Korge BP, Marenholz I, et al. Genes encoding structural proteins of epidermal cornification and S100 calcium-binding proteins form a gene complex ('epidermal differentiation complex') on human chromosome 1q21. J Invest Dermatol 1996;106: 989-992.

5 Elder JT, Zhao X. Evidence for local control of gene expression in the epidermal differentiation complex. Exp Dermatol 2002;11:406-412.

6 Gibbs S, Ponec M. Intrinsic regulation of differentiation markers in human epidermis, hard palate and buccal mucosa. Arch Oral Biol 2000;45:149-158.

7 Reddy SP, Konkin T, Wu R. Structure and organization of the genes encoding mouse small proline-rich proteins, mSPRR1A and 1B. Gene 1998;224:59-66.

8 Song HJ, Poy G, Darwiche N, et al. Mouse Sprr2 genes: a clustered family of genes showing differential expression in epithelial tissues. Genomics 1999;55: 28-42.

9 Tarcsa E, Candi E, Kartasova T, et al. Structural and transglutaminase substrate properties of the small proline-rich 2 family of cornified cell envelope proteins. J Biol Chem 1998;273:23297-23303.

10 Stern LE, Erwin CR, Falcone RA, et al. cDNA microarray analysis of adapting bowel after intestinal resection. J Pediatr Surg 2001;36:190-195.

11 Hooper LV, Wong MH, Thelin A, et al. Molecular analysis of commensal host-microbial relationships in the intestine. Science 2001;291:881-884.

12 Mueller A, O’Rourke J, Grimm J, et al. Distinct gene expression profiles characterize the histopathological stages of disease in Helicobacter-induced mucosaassociated lymphoid tissue lymphoma. Proc Natl Acad Sci USA 2003;100:1292-1297.

13 Tesfaigzi J, Carlson DM. Cell cycle-specific expression of G(0)SPR1 in Chinese hamster ovary cells. Exp Cell Res 1996;228:277-282.

14 Tan YF, Li FX, Piao YS, et al. Global gene profiling analysis of mouse uterus during the oestrous cycle. Reproduction 2003;126:171-182.

15 Robertson FG, Harris J, Naylor MJ, et al. Prostate development and carcinogenesis in prolactin receptor knockout mice. Endocrinology 2003;144:3196-3205. 
16 Bonilla IE, Tanabe K, Strittmatter SM. Small prolinerich repeat protein $1 \mathrm{~A}$ is expressed by axotomized neurons and promotes axonal outgrowth. J Neurosci 2002;22:1303-1315.

17 Liu Z, Sakamoto T, Ezure T, et al. Interleukin-6, hepatocyte growth factor, and their receptors in biliary epithelial cells during a type I ductular reaction in mice: interactions between the periductal inflammatory and stromal cells and the biliary epithelium. Hepatology 1998;28:1260-1268.

18 Liu Z, Sakamoto T, Yokomuro S, et al. Acute obstructive cholangiopathy in interleukin-6 deficient mice: compensation by leukemia inhibitory factor (LIF) suggests importance of gp-130 signaling in the ductular reaction. Liver 2000;20:114-124.

19 Rosen HR, Winkle PJ, Kendall BJ, et al. Biliary interleukin-6 and tumor necrosis factor-alpha in patients undergoing endoscopic retrograde cholangiopancreatography. Dig Dis Sci 1997;42:1290-1294.

20 Scotte M, Daveau M, Hiron M, et al. Interleukin-6 (IL$6)$ and acute-phase proteins in rats with biliary sepsis. Eur Cytokine Networks 1991;2:177-182.

21 Kimmings AN, van Deventer SJ, Obertop $\mathrm{H}$, et al. Endotoxin, cytokines, and endotoxin binding proteins in obstructive jaundice and after preoperative biliary drainage. Gut 2000;46:725-731.

22 Yasoshima M, Kono N, Sugawara H, et al. Increased expression of interleukin-6 and tumor necrosis factoralpha in pathologic biliary epithelial cells: in situ and culture study. Lab Invest 1998;78:89-100.

23 Akiyama T, Hasegawa T, Sejima T, et al. Serum and bile interleukin 6 after percutaneous transhepatic cholangio-drainage. Hepatogastroenterology 1998;45: 665-671.

24 Demetris AJ, Lunz JG, Subbotin V, et al. Participation of cytokines and growth factors in biliary epithelial proliferation and mito-inhibition during ductular reactions. In: Alpini G et al (eds). The Pathophysiology of the Biliary Epithelia. Landes Bioscience: Georgetown, TX, 2003, pp 167-191.

25 Ezure T, Sakamoto T, Tsuji H, et al. The development and compensation of biliary cirrhosis in interleukin-6deficient mice. Am J Pathol 2000;156:1627-1639.

26 Nozaki I, Lunz J, Specht S, et al. Trefoil factor family 3 expression and function in the biliary tree. Am J Pathol 2004;Dec (in press).

27 Poli V, Balena R, Fattori E, et al. Interleukin-6 deficient mice are protected from bone loss caused by estrogen depletion. EMBO J 1994;13:1189-1196.

28 Yokomuro S, Lunz JG, Sakamoto T, et al. The effect of interleukin-6 (IL-6)/gp130 signalling on biliary epithelial cell growth, in vitro. Cytokine 2000;12:727-730.

29 Yokomuro S, Tsuji H, Lunz III JG, et al. Growth control of human biliary epithelial cells by interleukin 6, hepatocyte growth factor, transforming growth factor beta1, and activin A: comparison of a cholangiocarcinoma cell line with primary cultures of non-neoplastic biliary epithelial cells. Hepatology 2000;32:26-35.

30 Park JI, Strock CJ, Ball DW, et al. The Ras/Raf/MEK/ extracellular signal-regulated kinase pathway induces autocrine-paracrine growth inhibition via the leukemia inhibitory factor/JAK/STAT pathway. Mol Cell Biol 2003;23:543-554.

31 Skelly SM, Tackney C, Hicklin D, et al. High-level expression of a biologically active human interleukin-6 mutein. J Biotechnol 1994;34:79-86.

32 Ni R, Nishikawa Y, Carr BI. Cell growth inhibition by a novel vitamin $\mathrm{K}$ is associated with induction of protein tyrosine phosphorylation. J Biol Chem 1998;273: 9906-9911.

33 Ishihara K, Hirano T. Molecular basis of the cell specificity of cytokine action. Biochim Biophys Acta 2002;1592:281-296.

34 Katou F, Shirai N, Kamakura S, et al. Differential expression of cornified cell envelope precursors in normal skin, intraorally transplanted skin and normal oral mucosa. Br J Dermatol 2003;148:898-905.

35 Dang Q, Gregersen H, Duch B, et al. Indicial response functions of growth and remodeling of common bile duct postobstruction. Am J Physiol Gastrointest Liver Physiol 2004;286:G420-G427.

36 Demetris AJ, Sakamoto T, Liu Z, et al. The ductular reaction in liver disease emphasis on a type I response. In: Fleig WE (ed). Normal and Malignant Liver Cell Growth. Kluwer Academic Publishers: Dordecht, 1999, pp 141-155.

37 Angelico M, De Sanctis SC, Gandin C, et al. Spontaneous formation of pigmentary precipitates in bile saltdepleted rat bile and its prevention by micelle-forming bile salts. Gastroenterology 1990;98:444-453.

38 Denson LA, Bohan A, Held MA, et al. Organ-specific alterations in RAR alpha:RXR alpha abundance regulate rat Mrp2 (Abcc2) expression in obstructive cholestasis. Gastroenterology 2002;123:599-607.

39 Hashmonai M, Kam I, Schramek A. The etiology of 'white bile' in the biliary tree. J Surg Res 1984;37: 479-486.

40 Ahuja V, Garg PK, Kumar D, et al. Presence of white bile associated with lower survival in malignant biliary obstruction. Gastrointest Endosc 2002;55:186-191.

41 Birchmeier C, Birchmeier W, Gherardi E, et al. Met, metastasis, motility and more. Nat Rev Mol Cell Biol 2003;4:915-925.

42 Richards TG, Thomson JY. The secretion of bile against pressure. Gastroenterology 1961;40:705-707.

43 Barber-Riley G. Rat biliary tree during short periods of obstruction of common duct. Am J Physiol 1963;205: 1127-1131.

44 Ostrow JD. Biliary resorption of C14 bilirubin. J Lab Clin Med 1963;62:998-999.

45 Kalinin AE, Kajava AV, Steinert PM. Epithelial barrier function: assembly and structural features of the cornified cell envelope. Bioessays 2002;24:789-800.

46 Lin ZQ, Kondo T, Ishida Y, et al. Essential involvement of IL-6 in the skin wound-healing process as evidenced by delayed wound healing in IL-6-deficient mice. J Leukoc Biol 2003;73:713-721.

47 Ernst M, Inglese M, Waring P, et al. Defective gp130mediated signal transducer and activator of transcription (STAT) signaling results in degenerative joint disease, gastrointestinal ulceration, and failure of uterine implantation. J Exp Med 2001;194:189-203. 